\title{
First middle-atmospheric zonal wind profile measurements with a new ground-based microwave Doppler-spectro-radiometer
}

\author{
R. Rüfenacht, N. Kämpfer, and A. Murk \\ Institute of Applied Physics, University of Bern, Bern, Switzerland \\ Correspondence to: R. Rüfenacht (rolf.ruefenacht@iap.unibe.ch) \\ Received: 22 June 2012 - Published in Atmos. Meas. Tech. Discuss.: 24 July 2012 \\ Revised: 10 October 2012 - Accepted: 11 October 2012 - Published: 7 November 2012
}

\begin{abstract}
We report on the wind radiometer WIRA, a new ground-based microwave Doppler-spectro-radiometer specifically designed for the measurement of middleatmospheric horizontal wind by observing ozone emission spectra at $142.17504 \mathrm{GHz}$. Currently, wind speeds in five levels between 30 and $79 \mathrm{~km}$ can be retrieved which makes WIRA the first instrument able to continuously measure horizontal wind in this altitude range. For an integration time of one day the measurement error on each level lies at around $25 \mathrm{~m} \mathrm{~s}^{-1}$. With a planned upgrade this value is expected to be reduced by a factor of 2 in the near future. On the altitude levels where our measurement can be compared to wind data from the European Centre for Medium-Range Weather Forecasts (ECMWF) very good agreement in the long-term statistics as well as in short time structures with a duration of a few days has been found.

WIRA uses a passive double sideband heterodyne receiver together with a digital Fourier transform spectrometer for the data acquisition. A big advantage of the radiometric approach is that such instruments can also operate under adverse weather conditions and thus provide a continuous time series for the given location. The optics enables the instrument to scan a wide range of azimuth angles including the directions east, west, north, and south for zonal and meridional wind measurements. The design of the radiometer is fairly compact and its calibration does not rely on liquid nitrogen which makes it transportable and suitable for campaign use. WIRA is conceived in a way that it can be operated remotely and does hardly require any maintenance.

In the present paper, a description of the instrument is given, and the techniques used for the wind retrieval based on the determination of the Doppler shift of the measured atmospheric ozone emission spectra are outlined. Their reliability
\end{abstract}

was tested using Monte Carlo simulations. Finally, a time series of 11 months of zonal wind measurements over Bern $\left(46^{\circ} 57^{\prime} \mathrm{N}, 7^{\circ} 26^{\prime} \mathrm{E}\right)$ is presented and compared to ECMWF wind data.

\section{Introduction}

In mid- and high-latitude regions atmospheric circulation models show a strong zonal wind, with velocities up to beyond $100 \mathrm{~m} \mathrm{~s}^{-1}$ in the altitude range between 30 and $70 \mathrm{~km}$, reversing its direction in the time around equinox. The wind direction is mainly westward in summer and eastward in winter with velocities that are generally higher in winter. While the westward wind in summer is quite persistent, abrupt changes in the wind speed or even reversals of the zonal wind direction can be observed during winter. They are often related to sudden stratospheric warmings. An example of one year of zonal wind over Bern, Switzerland $\left(46^{\circ} 57^{\prime} \mathrm{N}\right.$, $\left.7^{\circ} 26^{\prime} \mathrm{E}\right)$, according to the European Centre for MediumRange Weather Forecasts (ECMWF) is given in Fig. 1.

Commonly the wind data for the upper stratosphere and lower mesosphere are extrapolated using models or calculated from measurements of the temperature field, but are not measured directly. Still, such measurements would allow direct observations of dynamic processes and thus provide a better understanding of the circulation in this altitude region where the zonal wind speed reaches a maximum (Dunkerton, 2000). Observations of middle-atmospheric winds are also expected to provide deeper insight in the coupling between the upper and the lower atmosphere, especially in the case of sudden stratospheric warming events (Manney et al., 2008). Furthermore, as the local chemical 




Fig. 1. Zonal wind over Bern $\left(46^{\circ} 57^{\prime} \mathrm{N}, 7^{\circ} 26^{\prime} \mathrm{E}\right)$ throughout the year 2010 according to ECMWF operational analysis data. Note the abrupt change in wind direction at the end of January above $50 \mathrm{~km}$ altitude.

composition of the middle atmosphere can be measured with high accuracy, wind data could be beneficial for the interpretation of the associated transport processes. In future, middleatmospheric wind measurements could help to improve atmospheric circulation models.

Despite the high wind velocities between 30 and $70 \mathrm{~km}$ apparent in Fig. 1, the measurement of wind profiles in this altitude range remains one of the more difficult problems in atmospheric measurement techniques and currently no continuously running technique exists. In the last few years efforts have been made to use data from the monitoring of infrasonic waves, mainly of such originating from volcanos, to determine correction factors to middle-atmospheric winds in existing models (Le Pichon et al., 2005a,b). One shot wind measurements in the middle atmosphere can be made by having recourse to rocket flights. Rockets can be used to deploy a falling target that can be tracked by ground-based radars (Müllemann and Lübken, 2005) or release a chemical trace whose position is then repeatedly determined by optical cameras (Chu et al., 2007). However, as such observations are very expensive in costs, they are only viable on a campaign basis and not suited for long-term monitoring.

In contrast to the lack of measurements in the middle atmosphere, a variety of techniques exists for wind measurements in the troposphere and lower stratosphere. Most common are balloon-borne sondes (e.g. Goldberg et al., 2004). Also ground-based radars (e.g. Luce et al., 2001; Hooper et al., 2008) and lidars (e.g. Gentry et al., 2000) can be used for wind measurements in this altitude range. SODAR (Sonic Detecting And Ranging) observations are generally limited to the lowermost part of the troposphere (e.g. Anandan et al., 2008).
There is also considerable number of possibilities for the measurement of wind velocities at altitudes above about $70 \mathrm{~km}$. They rely on spaceborne or ground-based interferometers, on microwave limb sounding Doppler radiometry, or on ground-based radar or lidar applications.

In particular, the spaceborne limb sounding interferometers WINDII (Gault et al., 1996b) and HRDI (Burrage et al., 1996) that were flown on the UARS satellite had been designed to measure wind down to 85 and $50 \mathrm{~km}$, respectively, by using the airglow of oxygen and hydroxyl. A spaceborne airglow instrument that is still in operation is TIDI on TIMED that is measuring from $70 \mathrm{~km}$ upward (Killeen et al., 2006). The ground based interferometer ERWIN measures wind at the altitudes of 85,94 and $97 \mathrm{~km}$ by using a similar approach as TIDI on three different emission lines (Gault et al., 1996a).

It has also been reported that satellite measurements based on microwave limb sounding from MLS on AURA can provide reliable wind data for the upper atmosphere down to $80 \mathrm{~km}$ height (Wu et al., 2008). This was accomplished by determining the Doppler shift of the $\sigma^{-}$and $\sigma^{+}$Zeeman lines of molecular oxygen around $118.75 \mathrm{GHz}$ profiting from the strong contrast between the sizable line amplitude and the cold limb background.

Further, wind measurements for the upper atmosphere are also provided by ground-based radars. Meteor radars exploit the reflection of radar waves at ionised particles in meteor trails that drift with the wind. Such particles are present down to altitudes of roughly $75 \mathrm{~km}$ (Jacobi et al., 2007). Incoherent scatter radars are designed for ionospheric observations, but in the event of very active auroral precipitation wind measurements down to as low as $60 \mathrm{~km}$ have been reported (Nicolls et al., 2010). Finally, medium and low frequency radars are able to measure wind down to the upper mesosphere by determining the drift of electron density irregularities (Briggs, 1980).

Finally, ground-based sodium lidars cover the altitude range from 85 to $100 \mathrm{~km}$ (Williams et al., 2004). Effort has been undertaken to extend the sensitive range of the already mentioned lidars for tropospheric observations to the middle atmosphere (Gentry et al., 2000), but only few measurements have been made on a regular basis. In particular, Souprayen et al. (1999) presented climatological wind data up to $50 \mathrm{~km}$. At present, the only instrument able to measure wind throughout the entire middle atmosphere is the so-called "Rayleigh/Mie/Raman" lidar located at ALOMAR research station in Andenes. Baumgarten (2010) presented a first data set of measurements made during polar night, but states that the system is designed to be operational also during daytime. However, in contrast to microwave radiometers, lidars cannot measure under overcast conditions.

The altitude ranges covered by the techniques described above are summarised in Fig. 2 wherein the data gap in the middle-atmosphere becomes obvious. Ground-based Doppler microwave radiometry has the 


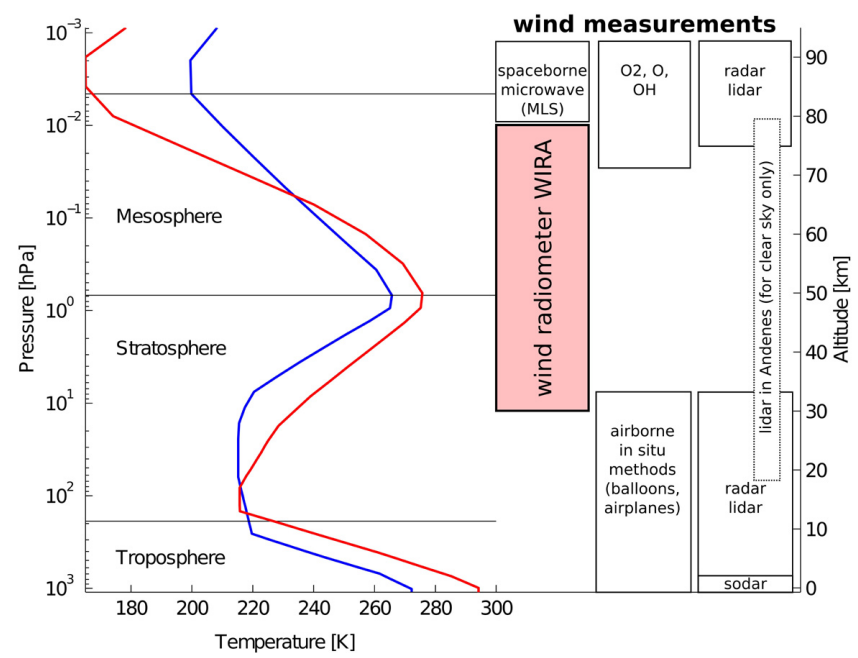

Fig. 2. Overview of the existing wind measurement techniques with their sensitive altitude range compared to the new wind radiometer WIRA. The blue and the red curve represent the temperature profile for mid-latitude winter and summer standard atmospheres. Under special conditions incoherent scatter radars may also be able to measure down to about $60 \mathrm{~km}$. Rocket measurements are not shown as they are only operated on campaign basis.

potential to contribute to the closing of this gap as proven by the new wind radiometer WIRA presented in this paper.

Direct measurements of mean mesospheric wind using microwave remote sensing techniques were published by Burrows (2007) from an experiment using a sub-millimeter telescope measuring $\mathrm{CO}$ at $461 \mathrm{GHz}$. The instrument was located in Antarctica at an altitude of $2847 \mathrm{~m}$, where the very dry troposphere ensures low absorption of the middle-atmospheric signal. Previously, Clancy and Muhlemann (1993) reported on the feasibility of wind measurements by ground-based microwave radiometry by referring to an experiment using the $\mathrm{CO}$ emission line at $230 \mathrm{GHz}$ wherefrom the mean zonal wind speed between 70 and $85 \mathrm{~km}$ altitude could be retrieved. However, none of the techniques mentioned here have to date been utilised as part of a regular measurement regime.

The Institute of Applied Physics of the University of Bern has a long experience in microwave remote sensing and aims to contribute to the development of Doppler wind radiometry. Ground-based radiometers for the measurement of middleatmospheric ozone and water vapour are operated on a routine basis within NDACC (Dumitru et al., 2006; Deuber et al., 2004; Straub et al., 2010; De Wachter et al., 2011). Ongoing developments in the field of low-noise receivers and stable narrowband spectrometers now offer the possibility of exploiting the sensitivity of ground-based microwave radiometry to signals from the middle-atmosphere for wind measurements by precisely determining the Doppler shift of emission lines of atmospheric constituents. As a precursor of our experiment Flury et al. (2008) measured lower mesospheric wind in November 2005 with the Airborne
Microwave Stratospheric Observation System (AMSOS) by assessing the Doppler shift of the peak of the $183.3 \mathrm{GHz}$ water vapor emission line.

Ground-based microwave radiometry has the advantage to offer long time series with good time coverage as it is largely independent of weather conditions and sunlight. Moreover, radiometers are relatively inexpensive and easy to use as stand alone devices. As a passive technique no transmitting equipment as necessary for lidars and radars is needed. This also allows a compact design and makes the instrument transportable and suitable for remote operation.

In the present paper the first section after the introduction describes the measurement principle and the instrumental setup of the new wind radiometer WIRA. The next section presents two different methods for the retrieval of horizontal wind in five middle-atmospheric altitude levels. Their accuracy has been tested using Monte Carlo simulations. Finally, a first time series of 11 month of wind data measured over Bern is presented and compared to ECMWF operational analysis data.

\section{The measurement principle}

\subsection{Doppler shift signature in emission spectra}

Our measurement principle is based on the determination of the Doppler shift $\Delta v$ of the emission signal from the rotational transition of atmospheric ozone at $142.175 \mathrm{GHz}$ measured by a ground-based microwave radiometer. The frequency shift is not only proportional to the line of sight wind speed $v_{\mathrm{LOS}}$, but also to the frequency of the measured electromagnetic signal $v_{0}$ :

$\Delta v=\frac{v_{\mathrm{LOS}}}{c} v_{0}$.

For the commonly encountered wind velocities, $\Delta v$ is six orders of magnitude smaller than the observation frequency $\nu_{0}$. As an example, at our observation frequency a line of sight wind speed of $50 \mathrm{~m} \mathrm{~s}^{-1}$ leads to a Doppler shift of $\Delta v=$ $23.7 \mathrm{kHz}$.

Due to the proportionality $\Delta v \propto v_{0}$ a high observation frequency would be preferable. We decided to use the $142 \mathrm{GHz}$ emission line of ozone because in this frequency range the troposphere is more transparent than at higher frequencies and because the middle-atmospheric ozone emission signal is comparatively high. This leads to a spectrum with steep line wings which is an advantage in terms of signal to noise ratio for the determination of the Doppler shift. Figure 3 shows the emission spectrum of the atmosphere for the mid latitudes in summer and winter to illustrate the reason for the choice of our observation frequency. Due to the high amount of water vapour in the troposphere the $183 \mathrm{GHz}$ emission line as measured by Flury et al. (2008) from an aircraft is not suitable for a ground-based instrument because the atmosphere 


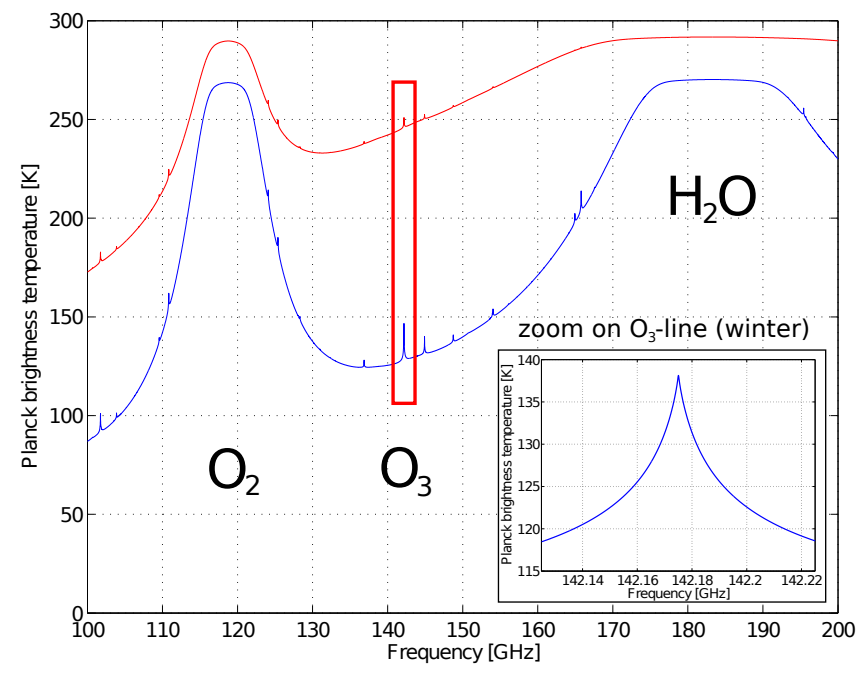

Fig. 3. The emission spectrum of the atmosphere in $20^{\circ}$ elevation for a mid-latitude winter (blue) and summer (red) standard atmosphere calculated using ARTS (Buehler et al., 2005). The ozone line used for our experiment is marked by the red rectangle.

seen from the earth surface is completely opaque at this frequency, except under extremely dry conditions. The oxygen emission line at $118 \mathrm{GHz}$ also is opaque when observed from low altitudes.

The pressure broadened emission line as observed by a ground-based instrument contains signals from the different atmospheric layers that contribute according to the radiative transfer equation (e.g. Janssen, 1993). The contribution from each layer is also Doppler shifted according to the local line of sight wind. This allows altitude dependent wind speed information to be retrieved.

\subsection{The instrument}

The wind radiometer WIRA can be divided into three parts. The optics and the frontend electronics are located outdoors (see Fig. 4) whereas the backend electronics are placed inside a laboratory. WIRA is designed to take measurements from opposite azimuthal directions, i.e. from west and east for the determination of the zonal wind component, and from north and south for the meridional component, in order to exclude systematic errors. The whole instrument can be remotely controlled.

\subsubsection{The frontend and backend electronics}

A block diagram of our receiver electronics is displayed in Fig. 5. It is a double sideband heterodyne receiver mixing the radio frequency (RF) of $142.17504 \mathrm{GHz}$ down to the intermediate frequency (IF) of $3.7 \mathrm{GHz}$ by the means of a lownoise subharmonic mixer fed by a PLL controlled local oscillator (LO) at $72.93764 \mathrm{GHz}$. With this LO configuration, the signal from the ozone emission line lies in the lower

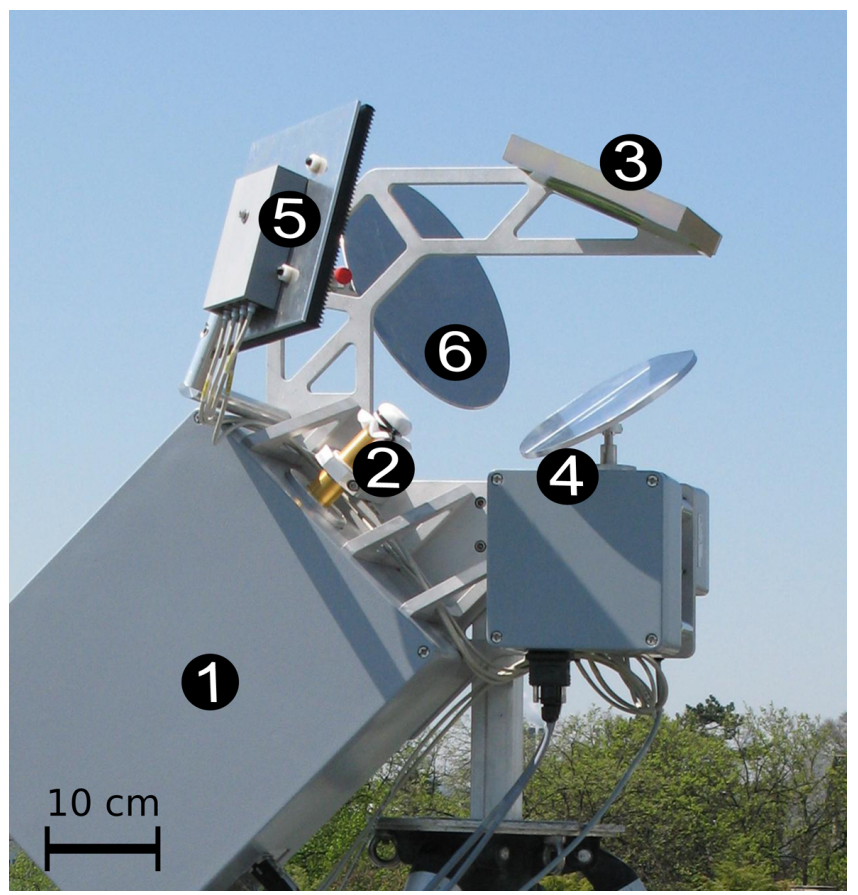

Fig. 4. WIRA's frontend and optics. 1: Frontend case, 2: Horn antenna, 3: Parabolic reflector, 4: Slewable plane mirror and driving motor, 5: Ambient temperature calibration load, 6: Plane zenith/nadir mirror for calibration.

sideband. The image sideband centred around $149.576 \mathrm{GHz}$ is not rejected. However, the signal contained in this sideband is nearly frequency independent within the small observation bandwidth and can thus be regarded as a bias to the spectrum. In any case, contributions from the image sideband do not hinder wind measurements when using spectra from two opposite viewing directions, even if they were slightly dependent on frequency. The $3.7 \mathrm{GHz}$ IF is transmitted to the backend, located indoors, through a $15 \mathrm{~m}$ long cable. There it is mixed down to $51 \mathrm{MHz}$ to be fed to a digital FFT spectrometer with $100 \mathrm{MHz}$ bandwidth and $6.1 \mathrm{kHz}$ resolution. $6.1 \mathrm{kHz}$ corresponds to the Doppler shift induced by a horizontal wind velocity of $13.9 \mathrm{~m} \mathrm{~s}^{-1}$ according to Eq. (2). The receiver noise temperature of the entire system in its operational mode typically lies around $900 \mathrm{~K}$.

To allow the instrument to look in opposite azimuth directions the optics and thus also the frontend for the processing of the high frequency signal have to be placed outdoors, with all the constraints concerning the weather resistance and temperature stability of the electronics that go with it. Nevertheless WIRA can operate under most climatic conditions encountered from subtropic to arctic latitudes thanks to its active thermal stabilisation that keeps gain variations small. Allan standard deviation measurements revealed that gain fluctuations start to dominate over noise for integration times $>700$ s only. Our standard measurement cycle performs all desired sky observations and the measurement of 


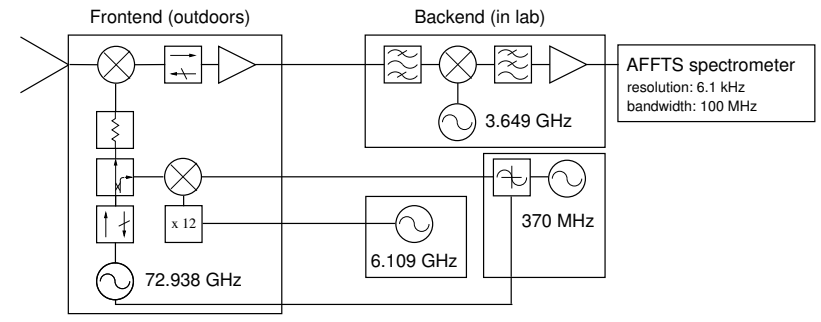

Fig. 5. Block diagram of WIRA's receiver electronics.

the calibration targets within one minute and is thus on the safe side, far before gain drifts begin to have significant influence.

The stability of our frequency sources was compared to a GPS reference signal over a three days period and is summarised in Table 1. For the first two sources mentioned in this table the instability is largely dominated by long-term drifts rather than short time variabilities. The short duration of one measurement cycle that comprises the observations in the opposite azimuthal directions makes their effect on the error in the wind negligible. This is not the case for the IF converter local oscillator, which leads to a maximum uncertainty in the wind of $1.4 \mathrm{~m} \mathrm{~s}^{-1}$. However, this value is one order of magnitude smaller than the errors induced by radiometric noise for the daily average wind speeds as will be demonstrated in Sect. 3.4. Noise is currently the most critical factor for wind radiometry, whereas high frequency resolution and stringent frequency stability can be achieved.

\subsubsection{The radiometric calibration}

The first calibration reference of WIRA is a pyramidal microwave absorber at ambient temperature. The requirement for the instrument to operate outdoors and to stay transportable makes it impractical to regularly use a cryogenic load as second reference target as done for most radiometers at this frequency. However, it has to be realised that the wind retrieval does not require the highest absolute calibration accuracy. We therefore use a simplified form of the tipping curve calibration scheme described by Schneebeli and Mätzler (2009). One standard measurement cycle implies the measurement of the sky in zenith, the sky at $22^{\circ}$ in two or four opposite azimuthal directions and a measurement of the ambient temperature load. As in this way the sky is observed under two different elevations only, no corrections for atmospheric inhomogeneities are possible. Therefore, the actual calibration accuracy would not be high enough for ozone profile retrieval, especially under cloudy conditions, but is sufficient for our purpose. Care has to be taken to preserve the frequency information during calibration. As every measurement of the sky other than zenith inherently contains the signature of horizontal wind, it is necessary to use the mean over two spectra from opposite viewing directions in the calibration procedure, in order to avoid an overestimation of wind speeds.
Table 1. Drifts over three days of the frequency sources (difference between minimum and maximum value normalised by the mean frequency) and their influence on the accuracy of the radio frequency RF.

\begin{tabular}{lcc}
\hline $\begin{array}{l}\text { Frequency } \\
\text { source }\end{array}$ & $\begin{array}{r}\text { Relative } \\
\text { accuracy }\end{array}$ & $\begin{array}{c}\text { Influence } \\
\text { on RF acc. }\end{array}$ \\
\hline LO in the PLL & $1 \times 10^{-8}$ & $1.4 \mathrm{kHz}$ \\
PLL reference & $3 \times 10^{-7}$ & $0.2 \mathrm{kHz}$ \\
LO of the IF converter & $1.6 \times 10^{-7}$ & $0.6 \mathrm{kHz}$ \\
\hline
\end{tabular}

In addition to the routine tipping curve calibrations the radiometer is occasionally calibrated with a liquid nitrogen target that can be accessed by changing the pointing of the plane mirror 6 in Fig. 4.

\subsubsection{The optical system}

An overview of WIRA's quasoptical system is given in Fig. 4. We opted for a system with a corrugated super gaussian horn antenna (Ade et al., 2009), a fixed parabolic reflector and a plane mirror slewable in azimuth. By allowing observations in opposite viewing directions for zonal and meridional wind, i.e. west-east and north-south, this design makes it possible to avoid systematic errors in the wind retrieval due to slight possible frequency drifts, frequency offsets, frequency dependences of the sideband ratio or standing waves in the signal path. In addition a contiguous range of $200^{\circ}$ of azimuth angle is observable. For optimal pointing accuracy all elements are directly mounted onto the same frame.

The sky is observed at an elevation of $22^{\circ}$. This offers the optimal compromise between high middle-atmospheric emission and moderate re-absorption by the troposphere for winter and summer, ensures a relatively small angle between the observing beam and a horizontal plane with a projection efficiency of horizontal wind of 0.93 , and avoids spurious signals from the horizon (trees, buildings, etc.) at most locations. This choice entails that the horizontal distance between the locations of the measurements from opposite viewing directions is $198 \mathrm{~km}$ for the signal coming from $40 \mathrm{~km}$ and $347 \mathrm{~km}$ for the altitude of $70 \mathrm{~km}$.

The optical system also includes an ambient temperature load and a mirror coupling in the beam from the sky in zenith direction or from a liquid nitrogen target for calibration. These elements are accessed through distinct position of the slewable mirror.

Compared to a one reflector design the chosen two reflector design offers lower beam asymmetries due to a smaller beam deflection angle at the focussing mirror and more flexibility in the sense that a future upgrade with elevation scanning remains possible by simply replacing the plane mirror. This would amongst others allow a more accurate calibration by making possible a full tipping curve scan. 


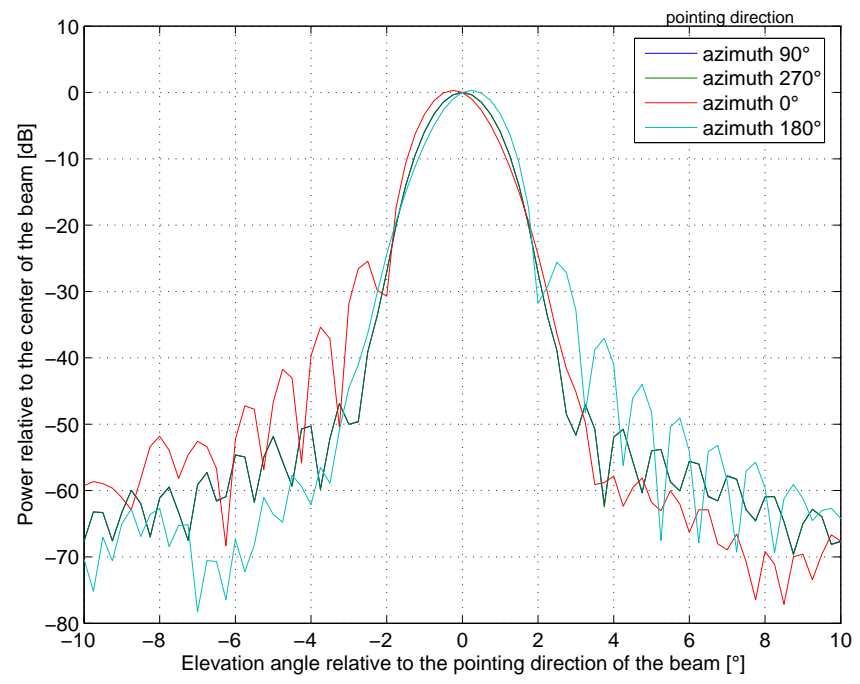

Fig. 6. Radiation pattern of the entire optical system in the elevational dimension for different positions of the slewable mirror, calculated with physical optics.

The challenge of this design was to find a combination of the horn and parabolic reflector properties, of the beam deviation angle at the focussing reflector, of the distances between the elements and of their size, that allows minimal spillover and self-shading, minimal beam asymmetries, and maximal angular resolution on the sky. This is important in order to guarantee that the wind measurements are not affected by other interfering factors or winds from other locations than expected.

The shading by all optical elements including horn and calibration targets was calculated to lie below $-47.9 \mathrm{~dB}$ for all positions of the slewable mirror. The spillover at the fixed focussing reflector is $-29.0 \mathrm{~dB}$ and below $-34.4 \mathrm{~dB}$ at the slewable mirror for all azimuthal positions and is negligible for the calibration target. The basis for these calculations using the physical optics software GRASP (Ticra, 2012) was the measured beam pattern of the horn antenna.

Figure 6 shows the radiation pattern of the entire optical system in the elevation plane simulated with GRASP. The 3-dB-beamwidth is $1.5^{\circ}$ and the 10 -dB-beamwidth $2.6^{\circ}$. At $10^{\circ}$ away from the centre of the beam, the signal has dropped to below $-60 \mathrm{~dB}$, so that we do not have to expect contamination of our measurements by the horizon. The small pointing offset of maximum $0.2^{\circ}$ and the one-sided broadening of the beam below the $25 \mathrm{~dB}$ level are due to the $45^{\circ}$ off-axis position of the parabolic reflector and are negligible for our purposes.

During the operation, WIRA's alignment and pointing errors have repeatedly been checked by scans of the sun of which azimuth and elevation are accurately known by the ephemerides. The wind error stemming from this source is not larger than $0.2 \%$.

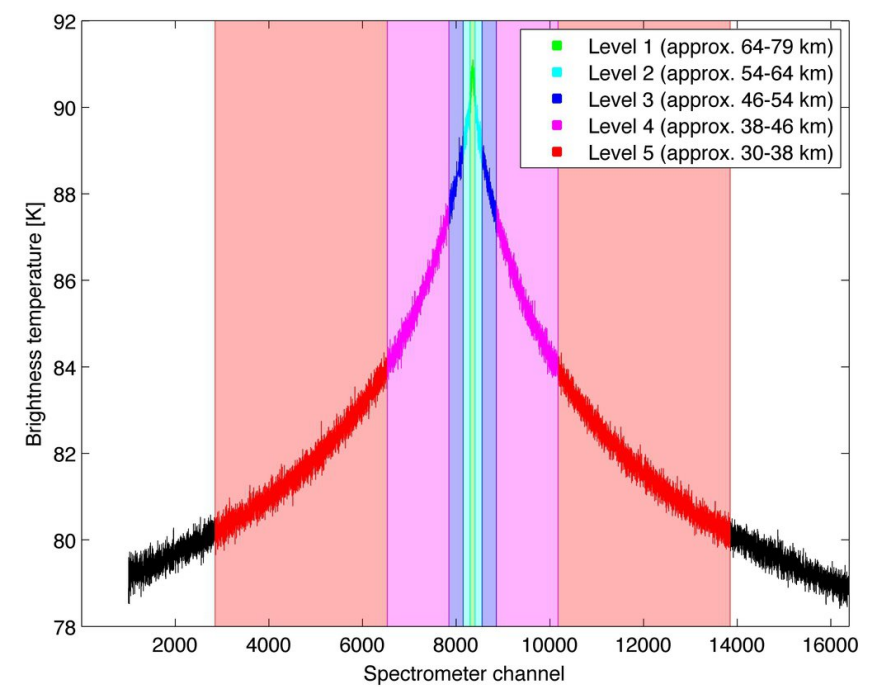

Fig. 7. Illustration of the choices of spectrometer channels $\mathcal{A}$ used in our standard wind retrieval. The spectrum plotted in black is the ozone emission spectrum at $142 \mathrm{GHz}$ measured by WIRA in westward direction on 7 February 2011 with an integration time of one day. The shaded areas of each colour correspond to the channels contained in $\mathcal{A}$ for the altitude level indicated in the legend.

\section{Retrieval methods for horizontal wind speed from ozone emission spectra}

WIRA observes the atmosphere in different azimuthal directions using a slewable mirror in its optical system. In the standard measurement schemes observations are made in the directions east and west or east, west, north and south. The following methods for retrieving the wind speed are based on the determination of the centre frequency of two calibrated ozone spectra from opposite observing directions, i.e. east and west for zonal wind and north and south for meridional wind. In this way systematic errors in the wind speed that could stem from instrumental instabilities, standing waves in the signal path or asymmetries of the measured spectra are avoided. For the determination of the centre frequency not an entire spectrum, but only parts of it are considered in order to obtain the Doppler shifts at different altitude levels (see Sect. 3.1). This is illustrated in Fig. 7 where the different parts of a spectrum are represented in different colours. These pieces of the spectra are referred to as partial spectra in the following. The spectra used for these operations are averages over time in order to reduce noise. The single measurements only contribute if they meet minimal quality standards in terms of signal to noise ratio and outliers.

Once the related centre frequencies have been determined, the corresponding horizontal wind velocity can easily be calculated using the Doppler effect according to Eq. (1) and the projection of the horizontal wind to the line of sight:

$v_{\text {wind }}=\frac{\delta v}{2 v_{0}} c \cdot \sec \epsilon$. 
$\delta \nu$ is the difference between the centre frequencies of the partial spectra from opposite observing directions which is twice the Doppler shift, $v_{0}$ is the line centre frequency in the absence of wind $(142.175 \mathrm{GHz}), c$ the speed of light and $\epsilon$ the elevation angle of the observation, in our case $22^{\circ}$. The vertical wind has been neglected because vertical wind speeds in this altitude range are known to be orders of magnitude smaller than horizontal winds and because the projection onto the line of sight is small due to the relatively low elevation angle.

The crucial point of the retrieval of wind speed in the different altitude layers is the accurate determination of the centre frequency in the partial spectra which is far from trivial in practice. Despite the considerable amount of noise, the shift of the spectra has to be determined with high accuracy as the commonly encountered wind speeds induce frequency shifts of a few channels only (a shift of one spectrometer channel in a single spectrum corresponds to a horizontal wind speed of $13.9 \mathrm{~m} \mathrm{~s}^{-1}$ in our measurement setup). Moreover the methods for the determination of the centre frequency should be robust in the sense that possible outliers on the measured spectra that were small enough to pass the outlier test on data read-in should have only a negligible influence on the determined centre frequency.

Several methods for the determination of the centre frequency have been developed and tested. Among them were different fitting methods which consist for example in fitting the measured spectra by a Lorentz curve or a spline fit on a quasi-logarithmic frequency scale as suggested by Lobsiger (1987), followed by a simple search for the maximum of the fit. However, the methods that were least affected by the radiometric noise were the mirror and the centroid method that are described in Sects. 3.2 and 3.3.

\subsection{Altitude dependent wind information}

Altitude dependent wind information is obtained by applying the retrieving techniques not to the entire spectrum, but only to a certain range of spectrometer channels $\mathcal{A}$. $\mathcal{A}$ is delimited by the half widths of the emission spectrum that correspond to the pressure at the lower and upper limits of the altitude range corresponding to the WIRA levels when the line shape is represented by a Voigt profile. This concept is illustrated by Fig. 7. The choice for the altitude levels is based on the averaging kernels of WIRA for the ozone profile retrieval whereof an example is shown in Fig. 8. The averaging kernels corresponding to the central altitudes of the WIRA levels for the wind retrieval are indicated in red. The limits of the altitude levels were set to the pressure where the averaging kernels drop below half of their maximum values. In this sense, these levels provide mostly independent information.

The approximative altitudes for the WIRA levels are 65$79 \mathrm{~km}$ for level 1, 54-64 km for level 2, 46-54 km for level 3, $38-46 \mathrm{~km}$ for level 4 , and $30-38 \mathrm{~km}$ for level 5 . As the Voigt profile directly depends on pressure rather than on

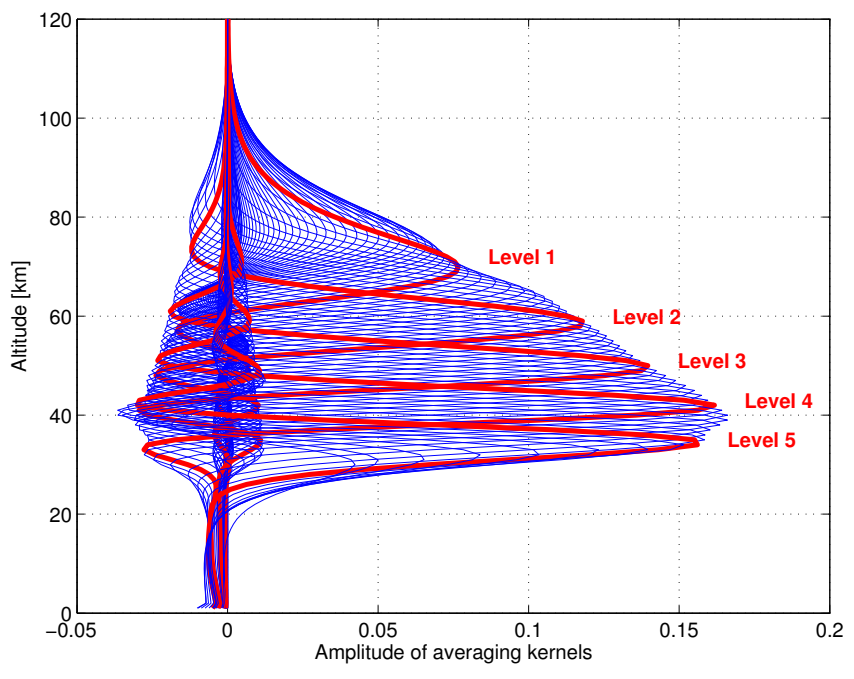

Fig. 8. Typical set of averaging kernels for the ozone profile retrieval from WIRA. The rows corresponding to the central altitudes of the wind levels are plotted in red.

geopotential height, these limits vary slightly in altitude but have fixed pressure values. Therefore, in practice the altitudes in geometrical units corresponding to the five levels are attributed according to the pressure profile measured by MLS on the AURA satellite on the respective day.

In the following two sections the methods used for the determination of the centre frequency of the parts of the spectrum in channel range $\mathcal{A}$ corresponding to the five WIRA altitude levels are described. From the centre frequencies the wind speed is then calculated according to Eq. (2).

\subsection{The mirror method}

This method assumes a mirroring frequency $v_{\text {test }}$ close to the peak frequency of the spectrum. The values of the brightness temperature of the partial spectrum right from this frequency are then subtracted from the values on the left. When this difference is zero the mirroring frequency corresponds to the centre frequency that we are looking for. Care has to be taken that the utilized spectrometer channels are distributed symmetrically around $v_{\text {test }}$. Mathematically the determination of the centre frequency with the mirror method corresponds to evaluating the function

$$
\begin{aligned}
& \chi\left(v_{\text {test }}\right)=\sum_{i}\left(T_{\mathrm{b}}\left(v_{\text {ind }}\left(v_{\text {test }}\right)-i\right)-T_{\mathrm{b}}\left(v_{\text {ind }}\left(v_{\text {test }}\right)+i\right)\right) \\
& \forall i \in\left\{i>0 \mid\left(\operatorname{ind}\left(v_{\text {test }}\right)+i\right) \in \mathcal{A} \wedge\left(\operatorname{ind}\left(v_{\text {test }}\right)-i\right) \in \mathcal{A}\right\}
\end{aligned}
$$

for different values of $v_{\text {test }}$ and finding $v_{\text {centre }}$ where $\chi\left(v_{\text {centre }}\right)=0$ by interpolation. The function ind $(v)$ attributes the index of a spectrometer channel to the frequency $v$ but is not an integer if $v$ does not lie in the centre of the according spectrometer channel. However, in our operational retrieval 
Table 2. Error in the retrieved daily average wind for a noise level of $0.23 \mathrm{~K}$ per channel on both daily average spectra. The underlying ozone profile corresponds to a mid-latitutde winter standard atmosphere.

\begin{tabular}{lcc}
\hline & Mirror & Centroid \\
\hline Level 1 (approx. 64-79 km) & $28.7 \mathrm{~m} \mathrm{~s}^{-1}$ & $29.0 \mathrm{~m} \mathrm{~s}^{-1}$ \\
Level 2 (approx. 54-64 km) & $24.7 \mathrm{~m} \mathrm{~s}^{-1}$ & $27.7 \mathrm{~m} \mathrm{~s}^{-1}$ \\
Level 3 (approx. 46-54 km) & $23.1 \mathrm{~m} \mathrm{~s}^{-1}$ & $27.1 \mathrm{~m} \mathrm{~s}^{-1}$ \\
Level 4 (approx. 38-46 km) & $19.6 \mathrm{~ms}^{-1}$ & $26.1 \mathrm{~m} \mathrm{~s}^{-1}$ \\
Level 5 (approx. 30-38 km) & $29.8 \mathrm{~ms}^{-1}$ & $42.1 \mathrm{~ms}^{-1}$ \\
Mean level 1-5 (approx. 30-79 km) & $11.4 \mathrm{~ms}^{-1}$ & $13.9 \mathrm{~m} \mathrm{~s}^{-1}$ \\
\hline
\end{tabular}

$v_{\text {test }}$ was chosen in a way to represent a channel, i.e. that $\operatorname{ind}\left(v_{\text {test }}\right) \in \mathbb{N}$, for convenience. $T_{\mathrm{b}}$ is the brightness temperature of the calibrated double sideband ozone emission spectrum. The fit used for the interpolation for determining the exact position of $\chi\left(v_{\text {centre }}\right)=0$ was chosen to be a third degree polynomial because it satisfactorily represents the curve and is less affected by noise than polynomials of higher degree. In practice $\chi$ was calculated for 61 assumptions for $v_{\text {test }}$ with a spacing of $6.1 \mathrm{kHz}$ before the interpolation.

\subsection{The centroid method}

The centroid method is similar to the retrieval technique applied by Flury et al. (2008). For the determination of the centre frequency $v_{\text {centre }}$ it performs a weighted average of the frequencies in the considered range $\mathcal{A}$ with the rescaled intensity $I(v)$ of the measured spectrum being the weights, what is an analogon to a centre of mass search. For these calculations a proper rescaling of the spectrum is essential. The intensity offset of the considered part of the spectrum has to be removed in order to avoid that it influences the determination of the centre frequency. The physical reason is that the intensity offset is only determined by the radiation originating from altitudes below the considered level. In practice, this rescaling is achieved by setting

$I\left(v_{i}\right)=T_{\mathrm{b}}\left(v_{i}\right)-T_{\mathrm{b}_{\min }}$

where

$T_{\mathrm{b}_{\min }}=\min \left(T_{\mathrm{b}_{\min }}^{1}, T_{\mathrm{b}_{\min }}^{\mathrm{r}}\right)$.

$T_{\mathrm{b}_{\text {min }}}^{1}$ and $T_{\mathrm{b}_{\text {min }}}^{\mathrm{r}}$ are the minima of linear fits to the right and the left wing of the spectrum within the range $\mathcal{A}$. The assumption of linearity is a sufficient approximation for these fits due to narrow frequency span covered by the different choices for $\mathcal{A}$. Higher order fits could affect the robustness of the method against noise especially for the uppermost levels. It is also necessary to rescale the frequency so that the possible gap in the range of $\mathcal{A}$ does not introduce artefacts in the retrieval result:
Table 3. Parameters of the fit WIRA $=a \mathrm{ECMWF}+b$ for the measurement period from 1 September 2010 to 31 July 2011. The data from WIRA are daily average zonal winds retrieved with the mirror method. The ECMWF operational analysis data were averaged to the WIRA levels.

\begin{tabular}{lcr}
\hline Fit paramters mirror & $a$ & $b$ \\
\hline Level 1 (approx. 64-79 km) & $0.70 \pm 0.03$ & $-1.01 \pm 1.73 \mathrm{~m} \mathrm{~s}^{-1}$ \\
Level 2 (approx. 54-64 km) & $1.04 \pm 0.03$ & $-0.44 \pm 1.90 \mathrm{~m} \mathrm{~s}^{-1}$ \\
Level 3 (approx. 46-54 km) & $1.00 \pm 0.03$ & $-2.98 \pm 2.01 \mathrm{~m} \mathrm{~s}^{-1}$ \\
Level 4 (approx. 38-46 km) & $0.96 \pm 0.03$ & $-0.73 \pm 1.41 \mathrm{~m} \mathrm{~s}^{-1}$ \\
Level 5 (approx. 30-38 km) & $0.97 \pm 0.07$ & $17.67 \pm 2.60 \mathrm{~m} \mathrm{~s}^{-1}$ \\
Mean level 1-5 & $0.98 \pm 0.02$ & $0.44 \pm 0.91 \mathrm{~m} \mathrm{~s}^{-1}$ \\
\hline
\end{tabular}

$\tilde{v}= \begin{cases}v-v_{\max }^{1} & \text { if } v \leq v_{\max }^{1} \\ v-v_{\min }^{\mathrm{r}} & \text { if } v \leq v_{\min }^{\mathrm{r}}\end{cases}$

where $v_{\max }^{1}$ and $v_{\min }^{\mathrm{r}}$ are the lower and upper edge frequencies of the gap in $\mathcal{A}$, if this gap exists. If there is no gap in $\mathcal{A}$, i.e. for level 1 (see Fig. 7), we set $v_{\max }^{1}=v_{\min }^{\mathrm{r}}=v_{0}$, what is the a-priori centre frequency, for convenience. In this sense we also define the value

$\bar{v}=\frac{v_{\max }^{1}+v_{\min }^{\mathrm{r}}}{2}$

for the back transformation to the physical frequency scale. An initial value for the centre frequency is given by

$v_{\text {centre }, 1}=\frac{\sum_{i} I\left(v_{i}\right) \tilde{v}_{i}}{\sum_{i} I\left(v_{i}\right)}+\bar{v} \quad \forall i \in\left\{i \in \mathcal{A} \mid I\left(v_{i}\right) \geq \xi\right\}$

where the threshold condition $I(v) \geq \xi$ is necessary to ensure that $v_{\text {centre }}$ is dominated by the measurement and not by the symmetry of the choice of the range $\mathcal{A}$ around the centre frequency. In our case the threshold was set to the mean value of the rescaled spectrum in the considered range $\mathcal{A}$

$\xi=\frac{\sum_{i \in \mathcal{A}} I\left(v_{i}\right)}{\operatorname{size}(\mathcal{A})}$.

With this choice approximately $50 \%$ of the values contained

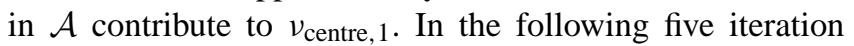
steps the centroid formula is evaluated symmetrically around the centre frequency considering all values within $\mathcal{A}$ to get a more accurate and robust estimate for $v_{\text {centre: }}$ :

$v_{\text {centre }}=\frac{\sum_{i \in \mathcal{A}^{\prime}} I\left(v_{i}\right) \tilde{v}_{i}}{\sum_{i \in \mathcal{A}^{\prime}} I\left(v_{i}\right)}+\bar{v}$

where $\mathcal{A}^{\prime}=\left\{i \in \mathbb{N} \mid\left(a_{\mathrm{c}}-r_{1}\right) \leq i \leq\left(a_{\mathrm{c}}-r_{2}\right)\right\} \cup\left\{i \in \mathbb{N} \mid\left(a_{\mathrm{c}}+\right.\right.$ $\left.\left.r_{2}\right) \leq i \leq\left(a_{\mathrm{c}}+r_{1}\right)\right\}$ with $a_{\mathrm{c}}=\operatorname{round}\left(\operatorname{ind}\left(v_{\mathrm{c}}\right)\right)$ where $v_{\mathrm{c}}=$ $v_{\text {centre, } 1}$ in the first iteration and $v_{\mathrm{c}}=v_{\text {centre }}$ in the following iteration steps. In this definition $r_{1}=\min ((\max (\mathcal{A})-$ $\left.\left.a_{\mathrm{c}}\right),\left(a_{\mathrm{c}}-\min (\mathcal{A})\right)\right)$ and $r_{2}=\max \left(\min \left(\left\{a_{\mathrm{c}}-i \mid i \in \mathcal{A} \wedge i \leq\right.\right.\right.$ $\left.\left.\left.a_{\mathrm{c}}\right\}\right), \min \left(\left\{i-a_{\mathrm{c}} \mid i \in \mathcal{A} \wedge i \geq a_{\mathrm{c}}\right\}\right)\right)$. 

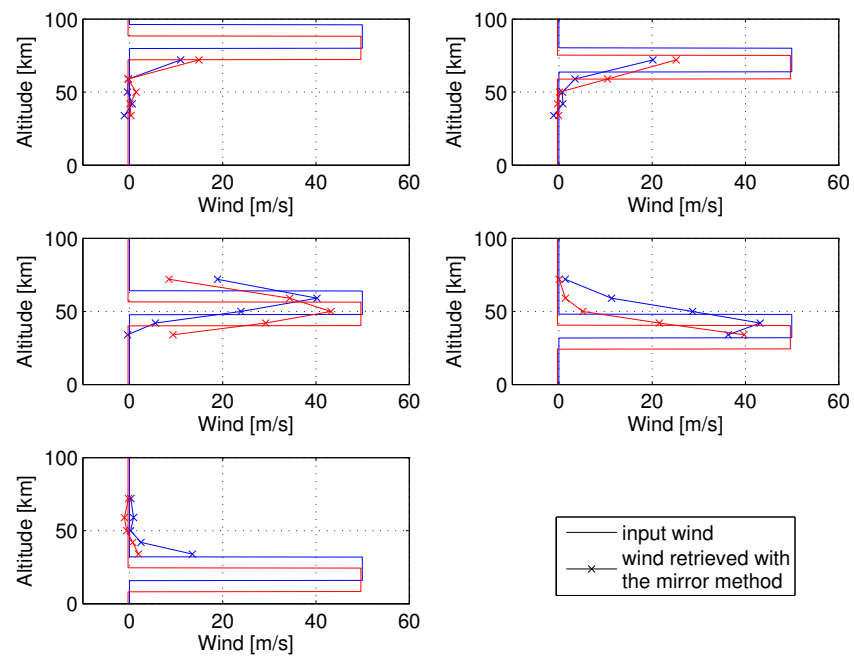

Fig. 9. Ten different input wind profiles with the corresponding retrieved winds for the mirror method. The input wind profile and the associated retrieved winds are plotted in the same colour. The markers for the retrieved wind are positioned at the central altitudes of the WIRA levels.

\subsection{Error analysis}

For the error analysis of the wind retrieval methods, Monte Carlo simulations were carried out. For this purpose, $142 \mathrm{GHz}$ emission lines of ozone corresponding to a mid-latitude winter standard atmosphere as measured with a double-sideband radiometer were calculated based on a synthetic wind profile for two opposite observing directions using a combination of ARTS (Buehler et al., 2005) and MATLAB code. Thereafter a certain amount of noise was added to the simulated spectra and the different retrieval methods were applied.

For an ensemble size of 10000 samples, wind profiles were retrieved when the noise added to the spectra was $0.23 \mathrm{~K}$ per channel what corresponds to the median of the noise level for all days that contribute to the 11 month wind time series presented in Sect. 4. The resulting standard deviations of the wind velocities in the different levels are shown in Table 2. It appears that the noise on the retrieved wind speed is slightly lower when using the mirror method compared to the centroid method which allows for more accurate conclusions to be drawn from the data, especially on the lower altitude levels. From the errors for this special case the errors in the wind data for any measurement condition can be calculated, because further simulations proved that they are proportional to the quantity $\sigma_{T_{\mathrm{b}}} / \Delta T_{\mathrm{b}}$ at least within the range of $\sigma_{T_{\mathrm{b}}}$ and $\Delta T_{\mathrm{b}}$ generally encountered in our measurements. The noise on the spectrum is given by $\sigma_{T_{\mathrm{b}}}$ and

$\Delta T_{\mathrm{b}}=T_{\mathrm{b}, \text { centre }}-T_{\mathrm{b}, \text { centre } \pm 45 \mathrm{MHz}}$

where $T_{\mathrm{b}, \text { centre }}$ is the measured brightness averaged over 600 spectrometer channels in the centre of the spectrum and
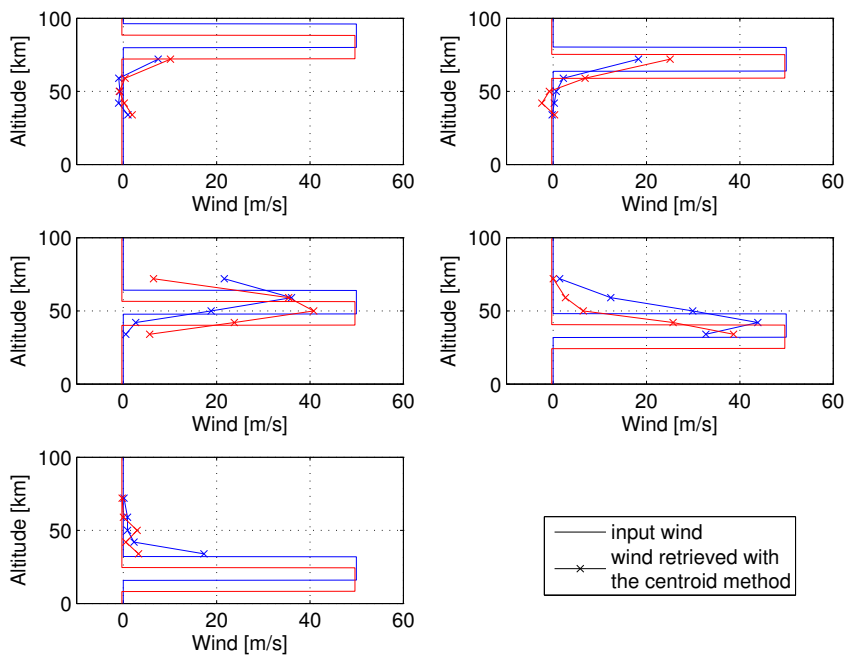

Fig. 10. Ten different input wind profiles with the corresponding retrieved winds for the centroid method. The input wind profile and the associated retrieved winds are plotted in the same colour. The markers for the retrieved wind are positioned at the central altitudes of the WIRA levels.

Table 4. Parameters of the fit WIRA $=a \mathrm{ECMWF}+b$ for the measurement period from 1 September 2010 to 31 July 2011. The data from WIRA are daily average zonal winds retrieved with the centroid method. The ECMWF operational analysis data were averaged to the WIRA levels.

\begin{tabular}{lcr}
\hline Fit paramters centroid & $a$ & $b$ \\
\hline Level 1 (approx. 64-79 km) & $0.77 \pm 0.04$ & $-1.23 \pm 1.97 \mathrm{~m} \mathrm{~s}^{-1}$ \\
Level 2 (approx. 54-64 km) & $0.96 \pm 0.04$ & $-0.20 \pm 2.27 \mathrm{~m} \mathrm{~s}^{-1}$ \\
Level 3 (approx. 46-54 km) & $0.95 \pm 0.04$ & $-2.03 \pm 2.33 \mathrm{~m} \mathrm{~s}^{-1}$ \\
Level 4 (approx. 38-46 km) & $0.92 \pm 0.04$ & $-1.88 \pm 2.03 \mathrm{~m} \mathrm{~s}^{-1}$ \\
Level 5 (approx. 30-38 km) & $1.13 \pm 0.10$ & $18.31 \pm 3.39 \mathrm{~m} \mathrm{~s}^{-1}$ \\
Mean level 1-5 & $0.97 \pm 0.02$ & $0.97 \pm 1.21 \mathrm{~m} \mathrm{~s}^{-1}$ \\
\hline
\end{tabular}

$T_{\mathrm{b}, \text { centre } \pm 45 \mathrm{MHz}}$ is the mean of the measured brightness temperatures at both edges of the spectrometer bandwidth averaged over 1500 channels. According to the mentioned proportionality the error of any wind measurement is given by

$\sigma=\sigma_{0} \frac{\Delta T_{\mathrm{b}, 0}}{\sigma_{T_{\mathrm{b}}, 0}} \frac{\sigma_{T_{\mathrm{b}}}}{\Delta T_{\mathrm{b}}}$

where $\sigma_{0}$ is the simulated wind error given in Table 2 . $\Delta T_{\mathrm{b}, 0}=8.32 \mathrm{~K}$ and $\sigma_{T_{\mathrm{b}}, 0}=0.23 \mathrm{~K}$ are the sharpness and the noise level of the underlying spectra for these simulations.

The simulations also proved that our retrieval methods did not produce any significant biases in the wind velocity. For a constant wind of $50 \mathrm{~m} \mathrm{~s}^{-1}$ between 3 and $100 \mathrm{~km}$ altitude the difference between the input wind speed and the mean of the retrieved wind from the 10000 sample ensemble was not higher than $3.2 \mathrm{~m} \mathrm{~s}^{-1}$ for the mirror method and $0.8 \mathrm{~m} \mathrm{~s}^{-1}$ for the centroid method on any of the five WIRA altitude levels. 

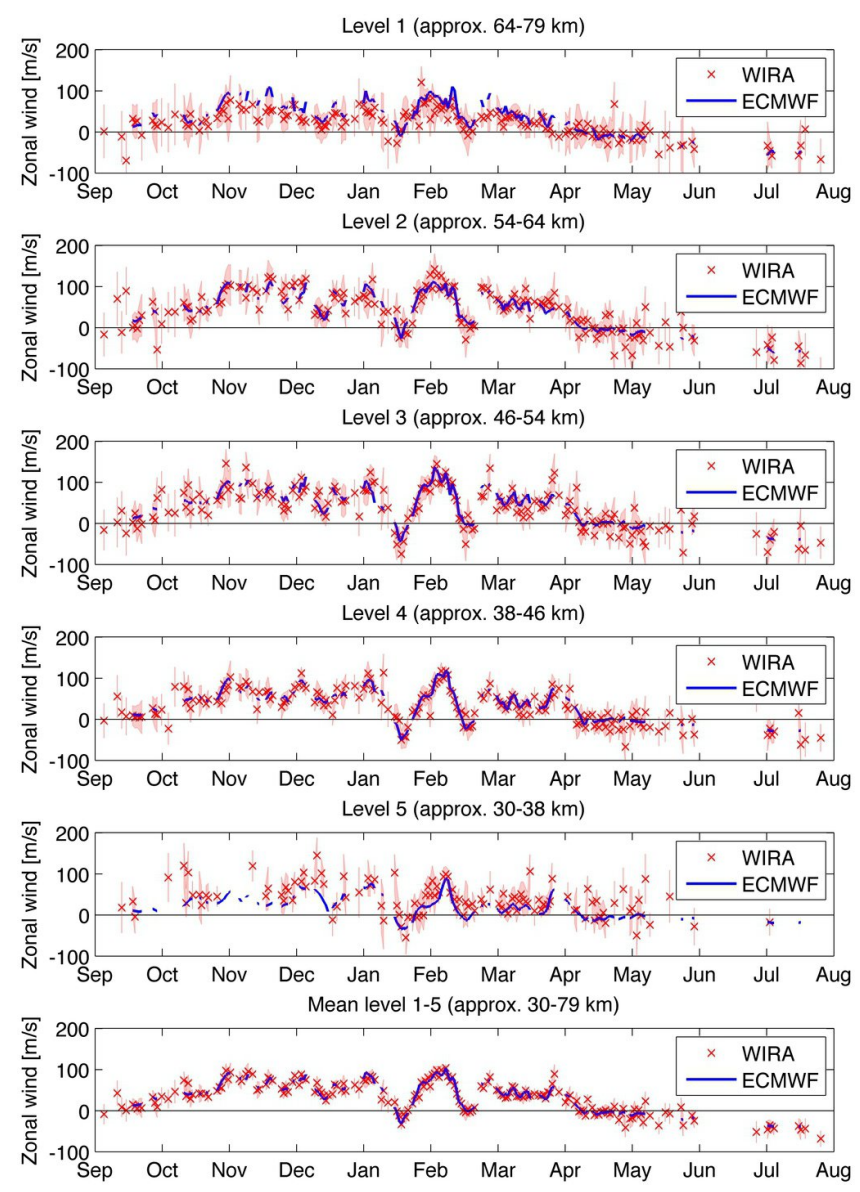

Fig. 11. Comparison of the data series from WIRA retrieved with the mirror method to the ECMWF operational analysis data for the standard WIRA levels and the mean over these altitude ranges. The data points are daily average winds. The $1 \sigma$-uncertainties are indicated by error bars.

The response of the wind retrieval methods to wind at different altitudes was tested using the same program set. To this end, the input wind profile was set to a constant value of $50 \mathrm{~m} \mathrm{~s}^{-1}$ in a $16 \mathrm{~km}$ broad altitude range and to $0 \mathrm{~m} \mathrm{~s}^{-1}$ at all other levels. The corresponding retrieval result for an ensemble of 1000 samples, again with a noise level of $0.23 \mathrm{~K}$ per channel of the daily average spectrum, is plotted in the same colour as the input wind profile in Fig. 9 for the mirror method and in Fig. 10 for the centroid method.

These figures prove that the wind retrievals are sensitive to the expected height. The fact that the retrieved wind never reaches the maximum input wind speed illustrates that the retrieval result is an average over a certain altitude range. This effect is particularly important for the uppermost WIRA level that has the largest extension in altitude.

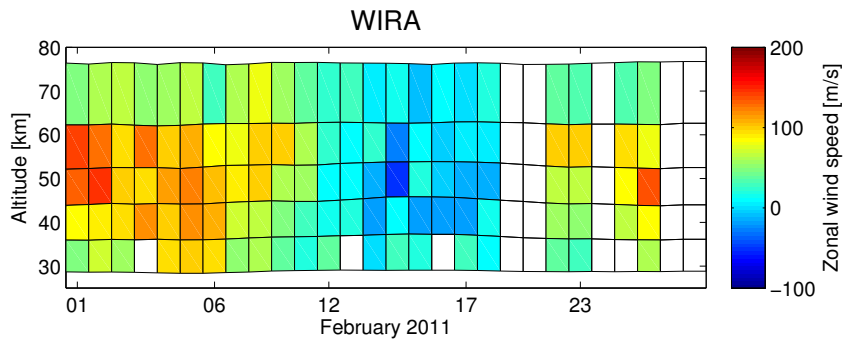

ECMWF

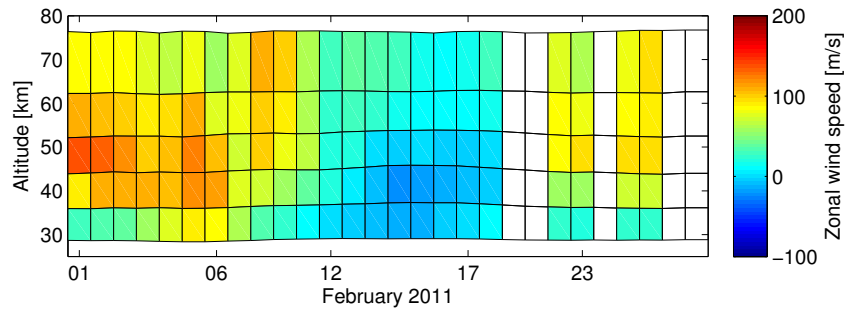

Fig. 12. Daily average zonal wind from WIRA retrieved with the mirror method for February 2011 compared to the data from the ECMWF operational analysis averaged to the WIRA levels.

\section{Measurement results}

Between 1 September 2010 and 31 July 2011 WIRA measured wind in its routine setup on the roof of our institute building in Bern ( $46^{\circ} 57^{\prime} \mathrm{N}, 7^{\circ} 26^{\prime} \mathrm{E}, 575 \mathrm{~m}$ a.s.l.). The data series of the zonal wind retrieved with the mirror and the centroid method described in Sects. 3.2 and 3.3 were compared to the ECMWF operational analysis data from the nearest grid point $\left(47^{\circ} 15^{\prime} \mathrm{N}, 7^{\circ} 53^{\prime} \mathrm{E}\right)$. In Fig. 11 the zonal wind for the entire measurement period from WIRA, retrieved with the mirror method, and from ECMWF is displayed. The measurement errors according to Eq. (12) are plotted as error bars.

The abrupt changes in the zonal wind in January and February 2011 were caused by the overpass of the edge of the polar vortex over Bern. They were found to be valuable test cases for our measurement approach. Therefore, for February 2011 the altitude dependent wind speed from WIRA is compared to ECMWF operational analysis data in pseudo colour plots in Fig. 12. Therein appears that even short time altitude dependent structures in our measurement correspond to the ECMWF data.

Figure 13 shows a scatter plot of the daily average zonal wind speeds between ECMWF and WIRA data retrieved with the mirror method for the entire measurement period. For comparison, in the lower left panel zonal wind data obtained from radiosondes launched in Payerne $\left(46^{\circ} 49^{\prime} \mathrm{N}\right.$, $6^{\circ} 57^{\prime} \mathrm{E}$, two radiosonde launches per day) that reached at least the lower limit of level 5 are plotted in red. The solid black lines indicate the linear fit between WIRA and ECMWF data with the measurements weighted by $1 / \sigma^{2}$ where $\sigma$ is the measurement error of the respective data point. The fit parameters and their errors are given in Table 3. 

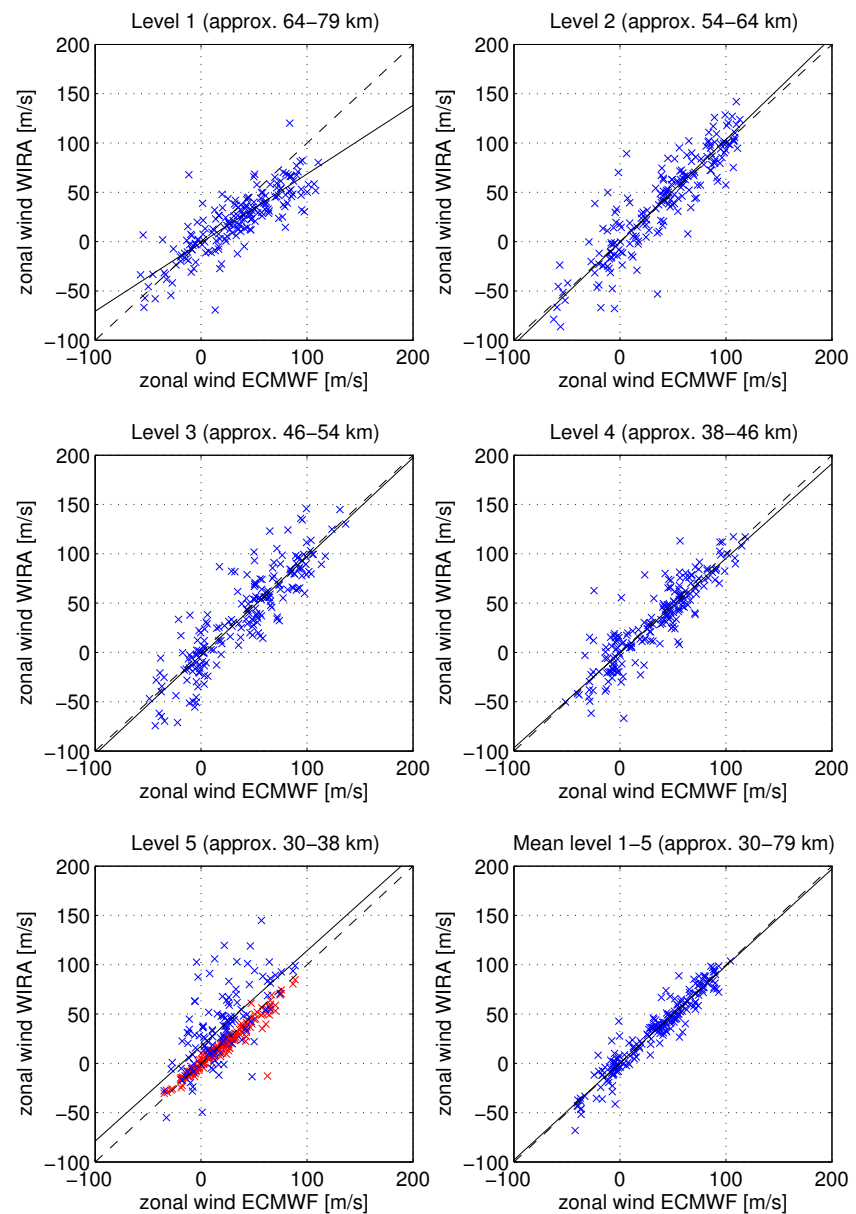

Fig. 13. Scatter plots between daily average WIRA winds retrieved with the mirror method and the ECMWF operational analysis data for the standard WIRA levels and the mean over these altitude ranges for the measurement period between 1 September 2010 and 31 July 2011. The solid black line is the fit through the data weighted with $1 / \sigma^{2}$ whereas the dashed line represents identity. The red markers in the panel for level 5 represent the data from the radiosondes from Payerne that reached the lower pressure limit of this level.

Except for the lowermost level, level 5, where the measurement uncertainty is highest, no significant bias (parameter $b$ ) exists between WIRA and ECMWF. Furthermore, the proportionality factor $a$ is very close to 1 for the mean over all levels and every individual level, except level 1. This discrepancy is expected to be due to the fact that WIRA is sensitive also to altitudes above the top of the range of available ECMWF data where wind speeds are expected to decrease rapidly with altitude in mid-latitude regions (Brasseur and Solomon, 2005).

The results obtained with the mirror method are confirmed by the wind speeds retrieved with the centroid method as shown by Fig. 14 and Table 4. Both methods agree within their errors. The slightly higher wind speeds that are retrieved
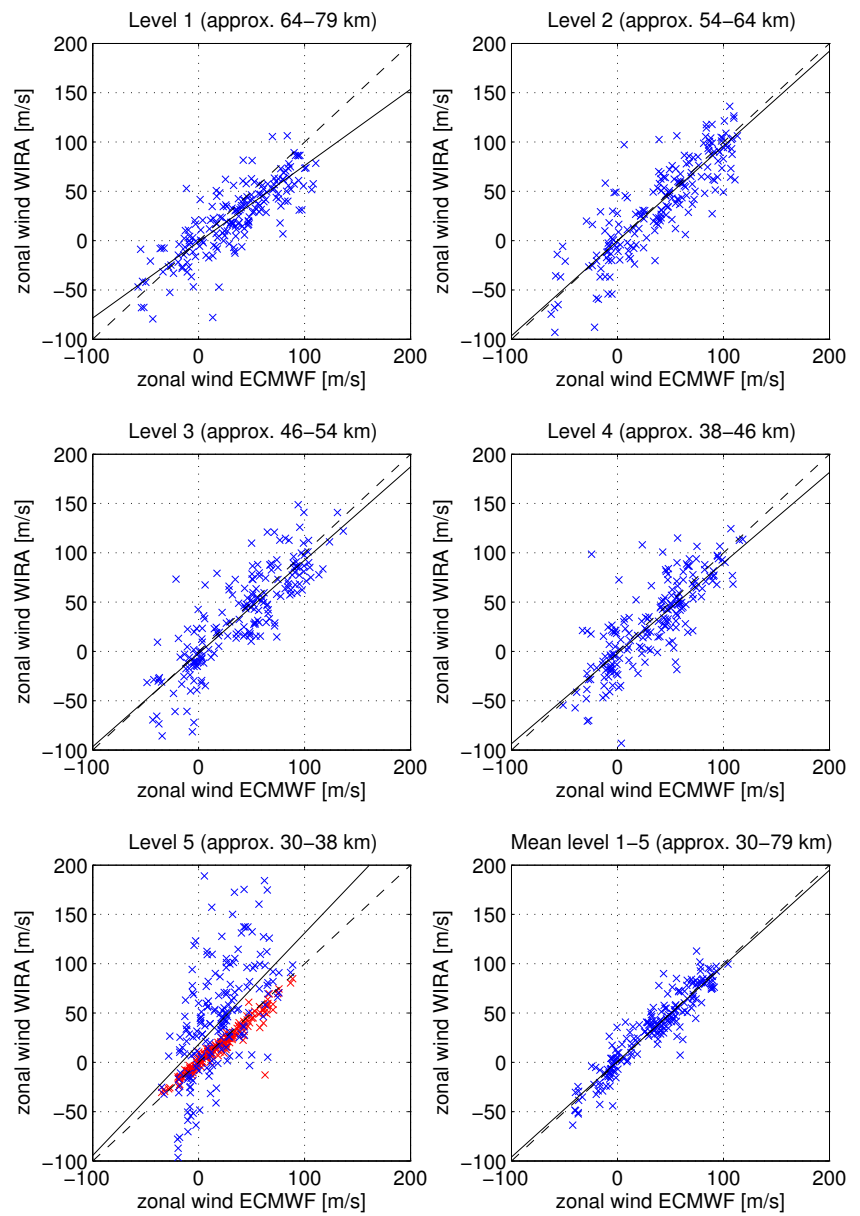

Fig. 14. Scatter plots between daily average WIRA winds retrieved with the centroid method and the ECMWF operational analysis data for the standard WIRA levels and the mean over these altitude ranges for the measurement period between 1 September 2010 and 31 July 2011. The solid black line is the fit through the data weighted with $1 / \sigma^{2}$ whereas the dashed line represents identity. The red markers in the panel for level 5 represent the data from the radiosondes from Payerne that reached the lower pressure limit of this level.

by the centroid method for level 1 could be due to the fact that it is a little less sensitive to higher altitudes than the mirror method, as is apparent when comparing the upper left panels of Figs. 9 and 10.

\section{Conclusions}

WIRA is a new ground-based microwave receiver for middle-atmospheric wind measurements. It aims to contribute to the significant data gap that exists between 40 and $70 \mathrm{~km}$ altitude for wind data. For the first time zonal wind profiles throughout the altitude range of $30-80 \mathrm{~km}$ have been continuously measured during 11 months. The instrumental noise and stability parameters are satisfactory although the 
signal to noise ratio will be improved with a planned upgrade. Thereby we expect to reduce the uncertainty of the retrieved wind speeds by a factor of 2 . The simplified calibration scheme's accuracy is high enough for wind measurements, and the presented retrieval methods were shown to have no bias with respect to the input wind profile of simulated spectra. Compared to the centroid method the mirror retrieval method provides wind data with slightly higher precision, especially for the lowermost altitude level. Comparing the 11 month long series of zonal wind data over Bern to the ECMWF operational analysis reveals very good statistical agreement. Also temporal and altitude dependent patterns in the zonal wind coincide in the data from WIRA and ECMWF.

Acknowledgements. This work has been supported by the Swiss National Science Foundation grant number 200020_134684/1. We acknowledge ECMWF for the operational analysis data, MeteoSwiss for the radiosonde data, and NASA for the pressure profiles measured by AURA MLS.

Edited by: G. Baumgarten

\section{References}

Ade, P. A., Wylde, R. J., and Zhang, J.: Ultra-Gaussian Horns for CIOVER - a B-Mode CMB Experiment, in: Twentieth International Symposium on Space Terahertz Technology, edited by: Bryerton, E., Kerr, A., and Lichtenberger, A., Charlottesville, 128 pp., 20-22 April 2009.

Anandan, V. K., Kumar, M. S., and Rao, I. S.: First results of experimental tests of the newly developed NARL phasedarray Doppler sodar, J. Atmos. Ocean. Tech., 25, 1778-1784, doi:10.1175/2008JTECHA1050.1, 2008.

Baumgarten, G.: Doppler Rayleigh/Mie/Raman lidar for wind and temperature measurements in the middle atmosphere up to 80 km, Atmos. Meas. Tech., 3, 1509-1518, doi:10.5194/amt-31509-2010, 2010.

Brasseur, B. H. and Solomon, S.: Aeronomy of the Middle Atmosphere, 3rd Edn., Springer, Dordrecht, 2005.

Briggs, B. H.: Radar observations of atmospheric winds and turbulence - a comparison of tecniques, J. Atmos. Terr. Phys., 42, 823-833, doi:10.1016/0021-9169(80)90086-0, 1980.

Buehler, S. A., Eriksson, P., Kuhn, T., von Engeln, A., and Verdes, C.: ARTS, the atmospheric radiative transfer simulator, J. Quant. Spectrosc. Ra., 91, 65-93, doi:10.1016/j.jqsrt.2004.05.051, 2005.

Burrage, M. D., Skinner, W. R., Gell, D. A., Hays, P. B., Marshall, A. R., Ortland, D. A., Manson, A. H., Franke, S. J., Fritts, D. C., Hoffman, P., McLandress, C., Niciejewski, R., Schmidlin, F. J., Shepherd, G. G., Singer, W., Tsuda, T., and Vincent, R. A.: Validation of mesosphere and lower thermosphere winds from the high resolution Doppler imager on UARS, J. Geophys. Res.-Atmos., 101, 10365-10392, doi:10.1029/95JD01700, 1996.
Burrows, S. M.: High-latitude remote sensing of mesospheric wind speeds and carbon monoxide, J. Geophys. Res.-Atmos., 112, D17109, doi:10.1029/2006JD007993, 2007.

Chu, Y. H., Su, C. L., Larsen, M. F., and Chao, C. K.: First measurements of neutral wind and turbulence in the mesosphere and lower thermosphere over Taiwan with a chemical release experiment, J. Geophys. Res.-Space, 112, A02301, doi:10.1029/2005JA011560, 2007.

Clancy, R. and Muhlemann, D.: Ground-based microwave spectroscopy of the Earth's stratosphere and mesosphere, in: Atmospheric Remote Sensing by Microwave Radiometry, edited by: Janssen, M. A., John Wiley, Chap. 7, 372-374, 1993.

De Wachter, E., Haefele, A., Kaempfer, N., Ka, S., Lee, J. E., and Oh, J. J.: The Seoul vapour radiometer for the Middle Atmosphere; calibration, retrieval and validation, IEEE T. Geosci. Remote, 49, 745-756, doi:10.1109/TGRS.2010.2072932, 2011.

Deuber, B., Kämpfer, N., and Feist, D. G.: A new 22$\mathrm{GHz}$ radiometer for Middle Atmospheric water vapour profile measurements, IEEE T. Geosci. Remote, 42, 974-984, doi:10.1109/TGRS.2004.825581, 2004.

Dumitru, C., Hocke, K., Kämpfer, N., and Calisesi, Y.: Comparison and validation studies related to ground-based microwave observations of ozone in the stratosphere and mesosphere, J. Atmos. Sol.-Terr. Phy., 68, 745-756, doi:10.1016/j.jastp.2005.11.001, 2006.

Dunkerton, T. J.: Midwinter deceleration of the subtropical mesospheric jet and interannual variability of the high-latitude flow in UKMO analyses, J. Atmos. Sci., 57, 3838-3855, doi:10.1175/1520-0469(2000)057<3838:MDOTSM>2.0.CO;2, 2000.

Flury, T., Hocke, K., Müller, S., and Kämpfer, N.: First measurements of lower mesospheric wind by airborne microwave radiometry, Geophys. Res. Lett., 35, L19802, doi:10.1029/2008GL034663, 2008.

Gault, W. A., Brown, S., Moise, A., Liang, D., Sellar, G., Shepherd, G. G., and Wimperis, J.: ERWIM: an eregion wind interferometer, Appl. Opt., 35, 2913-2922, doi:10.1364/AO.35.002913, 1996a.

Gault, W. A., Thuillier, G., Shepherd, G. G., Zhang, S. P., Wiens, R. H., Ward, W. E., Tai, C., Solheim, B. H., Rochon, Y. J., McLandress, C., Lathuillere, C., Fauliot, V., Herse, M., Hersom, C. H., Gattinger, R., Bourg, L., Burrage, M. D., Franke, S. J., Hernandez, G., Manson, A., Niciejewski, R., and Vincent, R. A.: Validation of $\mathrm{O}(\mathrm{S}-1)$ wind measurements by WINDII: the WIND imaging interferometer on UARS, J. Geophys. Res.-Atmos., 101, 10405-10430, doi:10.1029/95JD03352, 1996b.

Gentry, B. M., Chen, H. L., and Li, S. X.: Wind measurements with 355-nm molecular Doppler lidar, Opt. Lett., 25, 1231-1233, doi:10.1364/OL.25.001231, 2000.

Goldberg, R. A., Fritts, D. C., Williams, B. P., Lübken, F.J., Rapp, M., Singer, W., Latteck, R., Hoffmann, P., Mullemann, A., Baumgarten, G., Schmidlin, F.-J., She, C., and Krueger, D. A.: The MaCWAVE/MIDAS rocket and groundbased measurements of polar summer dynamics: overview and mean state structure, Geophys. Res. Lett., 31, L24S02, doi:10.1029/2004GL019411, 2004.

Hooper, D. A., Nash, J., Oakley, T., and Turp, M.: Validation of a new signal processing scheme for the MST radar at Aberystwyth, 
Ann. Geophys., 26, 3253-3268, doi:10.5194/angeo-26-32532008, 2008.

Jacobi, C., Froehlilch, K., Viehweg, C., Stober, G., and Kuerschner, D.: Midlatitude mesosphere/lower thermosphere meridional winds and temperatures measured with meteor radar, Adv. Space Res., 39, 1278-1283, doi:10.1016/j.asr.2007.01.003, 2007.

Janssen, M. A. (Ed.): Atmospheric Remote Sensing by Microwave Radiometry, John Wiley, 1993.

Killeen, T. L., Wu, Q., Solomon, S. C., Ortland, D. A., Skinner, W. R., Niciejewski, R. J., and Gell, D. A.: TIMED Doppler interferometer: overview and recent results, J. Geophys. Res.Space, 111, A10S01, doi:10.1029/2005JA011484, 2006.

Le Pichon, A., Blanc, E., and Drob, D.: Probing high-altitude winds using infrasound, J. Geophys. Res.-Atmos., 110, D20104, doi:10.1029/2005JD006020, 2005a.

Le Pichon, A., Blanc, E., Drob, D., Lambotte, S., Dessa, J. X., Lardy, M., Bani, P., and Vergniolle, S.: Infrasound monitoring of volcanoes to probe high-altitude winds, J. Geophys. Res.Atmos., 110, D13106, doi:10.1029/2004JD005587, 2005b.

Lobsiger, E.: Ground-based microwave radiometry to determine stratospheric and mesospheric ozone profiles, J. Atmos. Terr. Phys., 49, 493-501, doi:10.1016/0021-9169(87)90043-2, 1987.

Luce, H., Fukao, S., Yamamoto, M., Sidi, C., and Dalaudier, F.: Validation of winds measured by MU radar with GPS radiosondes during the MUTSI campaign, J. Atmos. Ocean. Tech., 18, 817-829, doi:10.1175/15200426(2001)018<0817:VOWMBM>2.0.CO;2, 2001.

Manney, G. L., Krueger, K., Pawson, S., Minschwaner, K., Schwartz, M. J., Daffer, W. H., Livesey, N. J., Mlynczak, M. G., Remsberg, E. E., Russell III, J. M., and Waters, J. W.: The evolution of the stratopause during the 2006 major warming: satellite data and assimilated meteorological analyses, J. Geophys. Res.Atmos., 113, D11115, doi:10.1029/2007JD009097, 2008.
Müllemann, A. and Lübken, F.-J.: Horizontal winds in the mesosphere at high latitudes, in: Coupling Processes in the MLT Region, vol. 35 of Adv. Space Res., 1890-1894, Comm. Space Res., Elsevier, UK, doi:10.1016/j.asr.2004.11.014, 35th COSPAR Scientific Assembly, Paris, 18-25 July 2004, 2005.

Nicolls, M. J., Varney, R. H., Vadas, S. L., Stamus, P. A., Heinselman, C. J., Cosgrove, R. B., and Kelley, M. C.: Influence of an inertia-gravity wave on mesospheric dynamics: a case study with the poker flat incoherent scatter radar, J. Geophys. Res.-Atmos., 115, D00N02, doi:10.1029/2010JD014042, 2010.

Schneebeli, M. and Mätzler, C.: A calibration scheme for microwave radiometers using tipping curves and Kalman filtering, IEEE T. Geosci. Remote, 47, 4201-4209, doi:10.1109/TGRS.2009.2023784, 2009.

Souprayen, C., Garnier, A., Hertzog, A., Hauchecorne, A., and Porteneuve, J.: Rayleigh-Mie Doppler wind lidar for atmospheric measurements, I.: Instrumental setup, validation, and first climatological results, Appl. Opt., 38, 2410-2421, doi:10.1364/AO.38.002410, 1999.

Straub, C., Murk, A., and Kämpfer, N.: MIAWARA-C, a new ground based water vapor radiometer for measurement campaigns, Atmos. Meas. Tech., 3, 1271-1285, doi:10.5194/amt-31271-2010, 2010.

Ticra: http://www.ticra.com/products/software/grasp (last access: 10 June 2012), 2012.

Williams, B. P., Fritts, D. C., Wang, L., She, C.-Y., Vance, J. D., Schmidlin, F. J., Goldberg, R. A., Mullemann, A., and Lübken, F.-J.: Gravity waves in the arctic mesosphere during the MaCWAVE/MIDAS summer rocket program, Geophys. Res. Lett., 31, L24S05, doi:10.1029/2004GL020049, 2004.

Wu, D. L., Schwartz, M. J., Waters, J. W., Limpasuvan, V., Wu, Q., and Killeen, T. L.: Mesospheric Doppler wind measurements from aura microwave limb sounder (MLS), Adv. Space Res., 42, 1246-1252, doi:10.1016/j.asr.2007.06.014, 2008. 